\title{
perifèria
}

Número 6, Julio 2007

www.periferia.name

\section{Meditaciones sobre el reino de lo político: Occidente, África y algunos debates contemporáneos ${ }^{1}$}

\author{
Ester Massó Guijarro - Universidad de Granada²
}

\section{Resumen}

Se presenta en este pequeño ensayo un conjunto de reflexiones sobre lo que ha significado lo político (el hecho y el espacio políticos) en la tradición de la filosofía política occidental, y sus correlatos en África.

Si bien son indudables los avances en el conocimiento y la comprensión de lo político desde este primer polo (Occidente), la indagación sobre los fenómenos políticos en África ha permanecido largo tiempo en un desconocimiento prepotente y reduccionista desde lo teórico y desde las miradas occidentales.

Se expondrá, entre otras consideraciones, la importancia de uno de los aspectos diferenciales clave para el espacio político africano en contraste con el espacio político occidental: la no separación entre lo personal (individual) y lo político (colectivo).

Resulta palmario hoy el rescate de África como un continente susceptible de ser abordado, estudiado y comprendido desde las diversas ciencias sociales en su amplitud, y no desde la reificación del humanitarismo paternalista o el folclorismo de lo exótico.

Palabras clave: teoría política occidental y africanista, identidades, reconciliación, globalización.

\begin{abstract}
Some thoughts about the significance of politics (the "political fact" and the "political space") in the tradition of the Western political philosophy, and its correlates in Africa, are presented in this brief essay.

The knowledge and the comprehension of politics from the Western tradition are undoubtedly well-known. Conversely, the research of the political phenomenon in Africa has remained uncovered for a long time both from theory and from Western perspective.

\footnotetext{
${ }^{1}$ Un germen inicial y muy abreviado de este artículo se halla en la comunicación [“Espacio político, memoria pública, re-conciliación: breve reflexión sobre la construcción de la identidad en la poscolonia") presentada por la autora en el II Congreso Panafricano de la Inmigración y las Comunidades negras (celebrado en Madrid del 1 al 4 de diciembre de 2005).

2 Enviar correspondencia a: Ester Massó Guijarro, ester@ugr.es
} 


\title{
perifèria
}

\author{
Número 6, Julio 2007
}

www.periferia.name

The non-separation between the personal and the political dimensions in the African political space, in contrast to the Western political space, will be exposed here, among others considerations, as one key issue for a proper understanding of the African Politics.

It is crucial nowadays the rescue of Africa as a continent susceptible of being addressed (studied, comprehended) from the Social Sciences and not from the reification of the paternalistic Humanitarianism or the Folklore of Exotics.

Key words: Western and African's Political Theory, identities, reconciliation, globalization.

\section{Obertura: pensando lo político desde distintos lugares}

\author{
La imaginación es el recurso del teórico para comprender un \\ mundo que jamás puede "conocer" de manera íntima [...] La \\ imaginación ha abarcado mucho más que la construcción de \\ modelos. Ha sido el medio para expresar los valores \\ fundamentales del teórico (Wolin, 2001, 28).
}

Una de las claves definitorias del espacio político occidental ha sido la neta separación entre lo personal y lo político ${ }^{3}$. Mas, ¿no puede significar esto una más de las esquizofrenias teóricas occidentales? La política la hacen las personas, que no están fuera del mundo ni exentas de consideraciones afectivas, prácticas, económicas... Tratar de escindir lo personal y lo político, ¿no vendría a constituir uno más de nuestros (inconcebibles desde otras culturas) formidables divorcios, como el del cuerpo y la mente, la razón y la emoción, el hombre-fuerte y la mujerdébil, la persona y el mundo... el bien y el mal, en definitiva? ${ }^{4}$

\footnotetext{
${ }^{3}$ Recordemos que la declaración "todo lo personal es político" fue estandarte emblemático de las luchas de liberación en muchos países africanos (vg. Mozambique), especialmente desde grupos feministas, pero no sólo.

${ }^{4}$ El bien y el mal, por ejemplo, están mucho más integrados en otras culturas. Esto puede observarse en el hecho de que la figura personificada del mal (demonios, figuras demonológicas en general) en culturas no occidentales no sea netamente mala sino que contenga también algunas vetas de bondad, que sea más bien ambigua, que se le pueda "comprar" con determinadas loas, que pueda uno congraciarse con ella para que le resulte venturosa... El mito demonológico de occidente, personificado en la figura del diablo judeocristiano, es por el contrario netamente maligno, negativo, sin veta alguna de ambigüedad ni posibilidad o conveniencia de "compra" o tratos (a pesar de su origen "de luz", como el ángel más hermoso).
} 


\section{perifèria}

Número 6, Julio 2007

www.periferia.name

Reflexionar sobre el espacio político involucra, o debería involucrar, una consideración sobre el vínculo entre lo personal y lo político, sobre la imbricación de los seres humanos en sociedad a través de la formación de las diferentes esferas relacionales menores (lo que se ha dado en llamar individual) y mayores (políticas y sociales), contando con grados intermedios.

En otras palabras, reflexionar sobre el espacio político implica considerar los modos de generación de las identidades políticas (personales y colectivas), ya que ellas determinarán cómo las personas perciben el hecho político y cómo se sienten frente a él (Arendt, 1974).

Si acudimos a los textos clásicos occidentales sobre teorías de lo político, hallaríamos las primeras definiciones rudimentarias -en Hobbes, Stuart Mill, Bentham, Mandeville incluso- de las realidades políticas que devendrían en Estadonación. Mucho antes incluso, encontramos abordajes e interpretación de lo político, del hecho político y lo que envuelve, desde Platón y Aristóteles.

Más reciente, podemos citar a Weber como uno de los grandes teóricos del Estado moderno y contemporáneo. El Estado weberiano implica una fuerza de poder (económico y militar) centralizada y monopolizada, así como una cierta moral calvinista del trabajo y la productividad. También acarrea nociones, más o menos intuitivas, sobre la consistencia profunda de un Estado democrático, de una nación y de lo que llamamos identidad nacional.

Frente a esto, la forma de abordar el hecho político en el continente africano se ha impuesto ya como claramente distinta, aunque este reconocimiento haya costado largos años de torpezas epistemológicas y "fraudes" heurísticos, a causa el empecinamiento en entender hechos políticos radicalmente dispares con un mismo lenguaje (teórico, interpretativo, comprehensivo, filosófico), a saber, el occidental.

Las corrientes subterráneas que alimentan este interrogante (el "fondo pantanoso" de lo político) son profundamente filosóficas, pese a lo que pudieran sugerir algunos otros de sus aspectos más carnales, mundanos o pragmáticos. Y lo son porque, forzosamente, a la base de cualquier perspectiva, teoría o noción de lo político (o hecho político, como lo llamo aquí, en analogía a la denominación "hecho religioso") se halla una determinada concepción de la persona, el mundo y sus 


\section{perifèria}

\section{Número 6, Julio 2007 \\ www.periferia.name}

relaciones; se encuentra una ontología del individuo, y una cosmovisión. Acaso la mayor diferencia que esto admita sea dónde se ponga el énfasis inicial: primero en la persona (individuo), primero en el mundo (comunidad o naturaleza), ¿o primero en sus relaciones? ${ }^{5}$ Parece que, desde la tradición occidental, este énfasis radicaba en el individuo y de él emanaban otras cuestiones, relaciones, obligaciones, derechos. Puede ser que aparezca como más propio de tradiciones africanas el énfasis primero en el grupo, en la comunidad ( $\sin$ que esto signifique que no exista en absoluto algún concepto de individuo) y que de ellos emanen las consideraciones acerca de las personas concretas ${ }^{6}$.

Sea como fuere, una concepción de lo político radica en una concepción de la ética y del mundo, del "deber ser", en fin (o, al menos, del "qué es más práctico que sea"), una noción de cómo son las personas (su identidad) y cómo se relacionan entre ellas y con el cosmos.

Así, estudiar la política en África probablemente sea estudiar (casi) todo su mundo, a causa de la no diferenciación (tan neta como en occidente, al menos) de esferas de realidad, según han sostenido los analistas (Chabal y Daloz, 1999, 203) ${ }^{7}$.

\footnotetext{
${ }^{5}$ Esta opción es hasta ahora la que menos ha fructificado, aunque pienso que podría ser la más interesante. Hallamos aproximaciones en la idea de rizoma de Deleuze y Guattari (1976), en teorías sistémicas como la de Morin (en Cyrulnik y Morin 2005), en aproximaciones plurales a la democracia como la de Boaventura de Sousa Santos (2000)...

6 "Hubo una época en la que, como todos los pueblos de la tierra, los africanos dirigían sus sencillas comunidades mediante jefes, aconsejados por asambleas tribales y reuniones públicas. En aquellos tiempos los jefes eran, sin duda, gobernantes representativos del pueblo" (Mandela, 2005, 107, 108). Sin querer caer en el manido idealismo de fuentes rousseaunianas de concebir la África precolonial como un todo armónico, sí resulta interesante considerar esta cita de Mandela especialmente por cuanto menciona a los "jefes" y el hecho de que eran "aconsejados" por el pueblo; aconsejados, pues, no determinados. Recordemos que algunos, como Iniesta, niegan la propiedad de atribuir valores propiamente democráticos al África precolonial, remarcando que el consenso no es democracia (el consenso, se afirma, es holista, sabio, lento, prudente y aparece en culturas tradicionales con un sentido profundo de la jerarquía; Iniesta, 2005; Dumont, 2000) El humanismo, base nutricia de la democracia, es un pensamiento dualista y por tanto no demasiado conciliable con tradiciones y sociedades africanas (Iniesta, 2005).

7 Se ha hablado de África como de un "rompecabezas epistemológico" que, sin embargo, el analista debe tratar de desagregar (Peñas Esteban, 2005), así como ha de detectar y cuestionar las "palabras-yugo" que a menudo no han hecho sino confundir y prejuzgar los estudios africanistas. Dos de estas palabrasyugo son la gobernabilidad (¿desde dónde y desde qué paradigmas se dictamina tal?) y, especialmente, la democratización (¿cómo se puede promover -forzar- un proceso de democratización desde fuera? ¿Dónde se pone el coto al derecho de injerencia, el etnocentrismo y la intención de promover una idea o sistema mediante vías que contradicen esa idea o sistema mismos?).
} 


\title{
perifèria
}

Número 6, Julio 2007

www. periferia. name

\section{Un esbozo del espacio político en Occidente: individuo y comunidad política}

\author{
Hace mucho que hemos perdido los nombres \\ verdaderos de las cosas (Catón, en Wolin, 2001, 100).
}

Hay cuestiones tan difícilmente aprensibles que sólo se puede hablar de ellas mediante alusiones; sólo se las puede referir o definir mediante circunloquios, es decir, rodeándolas. Algo así sucede con "lo político" en la tradición occidental, tan variada y cambiante como cualquier otra.

Resulta muy difícil escoger una definición, un solo modo de decir "lo político". El alcance de este trabajo es, además, pequeño, de modo que me conformaré con esbozar algunas líneas fundamentales que pueden considerarse cruciales en la demarcación de eso que es llamado "espacio político" en occidente.

Conviene señalar una cuestión fundamental previa, y es la condición meditativa y discursiva de la política en el mundo occidental, que ha "copado" un ámbito fundamental de la filosofía, a saber, el moral y el político. El politólogo norteamericano Sheldon Wolin Ilama a esta filosofía política una "tradición especial de discurso" (Wolin, 2001, 11). Dicho de otro modo, la política en occidente ha acarreado grandes dosis de reflexión, lo cual aporta un cierto carácter que la desmarca de una práctica meramente pragmática (valga la -aparenteredundancia). Tantos siglos de una especulación específica sobre la naturaleza del hecho político han complicado y enriquecido su comprensión en occidente, matizándola de un modo especial en un juego constante de neologismos, visión e imaginación teórica.

La tradición occidental, como se decía al comienzo, delimita netamente lo que es político que lo que no lo es, de otros ámbitos de autoridad o de participación asociativa, por ejemplo. Estos límites, sin embargo, han sido cambiantes y durante siglos (aún ahora, por supuesto) han ido redefiniéndose a la par que otras categorías y realidades sociales: 


\section{perifèria}

Número 6, Julio 2007

www. periferia. name

[...] El campo de la política es y ha sido, en un sentido decisivo y radical, un producto de la creación humana [...]. La teoría política no se interesa tanto en las prácticas políticas o en su funcionamiento como en sus significados [...]. De este modo, los conceptos y categorías que constituyen nuestra comprensión política [...] crean una zona de conocimiento determinado y con ello nos ayudan a separar los fenómenos pertinentes de los que no lo son (Wolin, 2001, 15) [la negrita es mía].

Para Hannah Arendt la definición de lo político viene dada por una determinada comprensión de la condición humana, gracias a la cual puede abrirse el espacio político. Son las condiciones humanas para la vida política las que la determinan tal y como es (Arendt, 1974). De ahí, la vieja idea de isonomía o isegoría ("hablar unos con otros"), heredada del mundo griego, no significa "tener todos los mismos derechos", sino "tener todos el mismo derecho a participar en política" (Arendt, 1974).

El filósofo político se ha esbozado a menudo desde la teoría como un apátrida, en cierto sentido y según ciertas perspectivas (como la kantiana), a causa de su cosmopolitismo o virtud cosmopolita - en tanto que no tiene compromiso por una polis concreta- (Palomar, 2005). Sin embargo, en occidente difícilmente se ha concebido la política desde una situación de desarraigo nacional: ¿cómo configurar comunidades políticas sin el recurso al arraigo, precisamente, de lo nacional? Incluso cuando lo nacional adopta aspectos aparentemente más neutrales: la comunidad política es para Dworkin, por ejemplo, el enraizamiento de los individuos a los actos jurídico-políticos de su comunidad (citado en Mouffe, 1993).

Una clave fundamental de lo político en Occidente es el papel de las instituciones, que otorgan al conjunto de fenómenos políticos y "pre-políticos" un cosmos, un orden que lo desmarca del caos originario que constituye la amalgama de fenómenos humanos antes de aquella diferenciación (Wolin, 2001). Así, estas

\footnotetext{
${ }^{8}$ Esta relación entre caos y cosmos posee profundas raíces en la filosofía griega y su aplicación al campo de lo político resulta muy esclarecedora. El filósofo político, a partir del caos político, afirma Wolin (2001, 17), modela un cosmos político: ordena el mundo de lo social en un sentido determinado.
} 


\section{perifèria}

Número 6, Julio 2007

www. periferia.name

instituciones vertebran el espacio político (como lugar donde se vinculan las fuerzas tensionales de la sociedad) y otorgan coherencia previa a los fenómenos políticos.

Las instituciones políticas son tales cuando se reconoce colectivamente su autoridad para tomar decisiones aplicables a toda la comunidad. $Y$, ¿cuándo las acciones y decisiones de los agentes que forman esta comunidad pasan a ser "políticas", y no de otra índole? Cuando se enclavan en la función "relacionante" que desempeñan las instituciones políticas, precisamente: "cuando esta toma de conciencia cobra la forma de una acción dirigida hacia las instituciones políticas, las actividades pasan a ser "políticas" y a integrar la naturaleza política" (Wolin, 2001, 16).

Además del espacio político, en la tradición occidental existe el "tiempo político", en el sentido de un período dentro del cual tienen lugar la decisión, la resolución o el acuerdo: "Ios ordenamientos políticos proporcionan así un marco dentro del cual se vinculan espacial y temporalmente las actividades de individuos y grupos" (Wolin, 2001, 16).

Otro de los aspectos cruciales de la política en occidente es la concepción del individuo y del ciudadano, tanto como su interactuación, ya que parecen estar en los polos respectivos de lo personal y lo colectivo. Así, las identidades entre individuo y ciudadano mantienen una ¿irreconciliable? tensión, como la libertad y la igualdad; sin embargo, precisamente estas tensiones caracterizan la democracia moderna. Cualquier intento de "armonía perfecta" es absurdo; sólo puede conducir a la destrucción por la tiranía del ideal, de lo utópico. Una nueva concepción democrática de ciudadanía podría restaurar la dignidad de lo político y proporcionar el vehículo de la construcción de una hegemonía radical (Mouffe, 1993, 105).

Los diferentes espacios de poder requieren una tierra en común (Wolin 2001). En congruencia con esta idea, el objetivo de una política democrática no sería tanto erradicar el poder cuanto multiplicar los espacios en los que las relaciones de poder estén abiertas a la contestación democrática; en definitiva, una apuesta por el pluralismo, en el dominio del Estado y en el de la sociedad civil (Mouffe, 1993).

Los modos de concebir la comunidad política y la referencia a la misma resumen las preguntas teóricas y práctica por la ciudadanía. Ésta, afirma Mouffe, debería ser concebida como una superficie discursiva y no como un referente empírico (Mouffe, 


\section{perifèria}

Número 6, Julio 2007

www. periferia. name

1993, 138) y en su conformación -entiéndase como universitas o como societasexiste forzosamente un mínimo compromiso de lealtad recíproca (Mouffe, 1993, 96), alguno de los tipos posibles de arraigo.

También de la filosofía griega se hereda la íntima vinculación entre lo ético y lo político. Ambas dimensiones se entienden como encaminadas al alcance de la "vida buena" ya explicitada por Aristóteles; y ambas se hallan en un paisaje común de valores individuales y colectivos. El carácter comunitario de lo político es fundamental, pues, pero también lo es la noción de individuo, que constituye algo así como su espina dorsal. Es necesariamente colectivo ("El poder político se ocupa de los intereses generales compartidos por todos los integrantes de la comunidad; Wolin, 2001, $19^{9}$ ), pero ese colectivo se nutre, también necesariamente, de individuos con "juicio" y criterio político ("El integrante de la sociedad puede compartir algunos intereses con sus semejantes, pero otros intereses pueden ser peculiares a él o a algún grupo al cual pertenece"; Wolin, 2001, 19). La tensión entre lo individual y lo colectivo es asimilable a la que se mencionaba entre individuo y ciudadano, o persona y ciudadano.

Frente a esto, conviene tener en cuenta que la práctica política occidental ha roto a menudo, y sigue haciéndolo, entre "lo político" y "la política" (Mouffe, 1993, 13,14), lo que obviamente implica una brecha de ruptura entre la política "real" y la filosofía de la misma. Tal vez haya de restablecerse la conexión entre la ética y política, acudiendo a su formulación más clásica, sin sacrificar las conquistas de la revolución democrática. (Mouffe, 1993, 95): “Lo ético-político es amplio porque resulta imposible inferir lo civilmente deseable a partir de los principios morales generales y la deliberación política tiene que ver con las consideraciones morales por sí mismas", afirma Oakeshott (en Mouffe, 1993, 99).

Conviene también reseñar el hecho la especificidad del lenguaje o vocabulario propios del campo de la política (y la filosofía política) en la tradición occidental (Wolin, 2001, 24). Tanto ciertos términos como su mismo uso trascienden la

\footnotetext{
${ }^{9}$ La cita sigue así: “[...] la autoridad política se diferencia de otras formas de autoridad en que habla en nombre de una sociedad considerada en sus características comunes" (Wolin, 2001, 19).
} 


\section{perifèria}

Número 6, Julio 2007

www. periferia. name

semántica propia de otras disciplinas o del empleo cotidiano, y esto se debe a los esfuerzos del teórico político por dimensionar un mundo desordenado y no clasificado, por otorgar, precisamente, "cosmos político" a la miscelánea de la realidad humana. Así, podría entenderse al analista político como un agrimensor de los fenómenos políticos.

Otra característica fundamental de lo político en occidente es, sin duda, su dimensión de la visión y la imaginación políticas (Wolin, 2001, 27), especialmente en su versión de las utopías. Wolin lo llama una "forma trascendente de perspectiva" (Wolin, 2001, 30), cuasi arquitectónica de lo social: ha existido un esfuerzo denodado en la tradición occidental por imaginar el paisaje político con todas sus texturas.

Debo insistir, llegado este punto, en que la riqueza de matices de las tradiciones políticas en occidente es enorme (de hecho, el modo más pertinente de nombrarlas es así, en plural). No pretendo abarcarlas todas aquí, ni mucho menos, como resultará obvio al lector; intentar reificarlas o unificarlas sería un ejercicio ocioso, en el mejor de los casos. La naturaleza y las concepciones de lo político en la Grecia clásica, en las distintas etapas del Medievo, en el Renacimiento, en el Romanticismo... poseen realmente tantas desemejanzas entre sí que, si se atiende a ellas, pueden difuminar enormemente las ciertas líneas diferenciales que se intenta entresacar para su contraste con las nociones de lo político en África. A pesar de esta traba, sigamos tratando de delinear nuestro paisaje.

En un contexto más o menos contemporáneo, muchos son los que denuncian un vacío político o una desfiguración del espacio político tradicional. Arendt pensaba que la capacidad meditativa del ser humano se pierde o, al menos, se difunde en la automatización de su vida cotidiana (Arendt, 1974). ¿Influirá en esta "pérdida de lo político" las condiciones tecnológicas de la vida actual en occidente?

Mouffe ha denunciado la incapacidad de la teoría de la democracia liberal para comprender los problemas actuales, en el sentido de que elude aquella realidad de los antagonismos, del poder de la vida social. Así, el liberalismo es visto como una evasión de lo político, adoleciendo de gran impotencia para captar su misma naturaleza. (Mouffe, 1993, 3). Además, la autora recoge algo de lo que ya se 


\section{perifèria}

Número 6, Julio 2007

www. periferia. name

preguntaba Arendt: ¿es posible hoy "evadirse" o desmarcarse del liberalismo? Pero, si no lo es, ¿cómo llegar del "yo" al "nosotros" que implica lo político? Esta pregunta, como resultará obvio al lector, cobra sentido desde una perspectiva o punto de partida individualista; en caso contrario sería ocioso formularla. No todo puede ser "político", sin embargo; la absolutización de la política puede destruir la política (con una consecuente banalización del mal) (Arendt, 1974).

¿Sucede en Occidente, hoy, una contaminación social de la política? ¿Es deseoso que suceda, para recuperar algo de lo intrínsecamente político que se heredó del mundo griego? ¿Hay una zona de mediación distinguible entre lo social y lo político? Resulta ya proverbial a estas alturas, aunque tal vez no (tan) ocioso, citar la diferencia entre la libertad de los antiguos y la libertad de los modernos que señalara Benjamin Constant (1919).

Consideremos el juego dialéctico que Chantal Mouffe establece entre antagonismo y agonismo, enemigo y adversario respectivamente, en la vida política de las sociedades actuales. El conflicto o, en palabras de Mouffe (1993), el agonismo, es ineludible en la arena política competencial (González Alcantud, 1998); pero esta noción de agonismo no es asimilable a la de antagonismo, que implica, según la comprensión de Mouffe, una resolución no inteligente de los conflictos (violencia simbólica, conceptual, física también; renuncia a la aceptación de que el conflicto constituye un entresijo de lo político y que debe dirimirse como tal).

Mouffe llama "exterior constitutivo", con gran acierto lingüístico a mi entender, a un hecho largamente reconocido y comprendido en los análisis politológicos y antropológicos de la realidad, a saber: que la condición de existencia de toda identidad es la afirmación de una diferencia, mediante la determinación de un "otro" que le servirá de "exterior" (foráneo, exógeno...) y que permitirá comprender la permanencia necesaria del antagonismo y sus condiciones de emergencia (Mouffe, 1993, 15). Toda identidad se construye, como sabemos, a través de parejas de diferencias jerarquizadas y mediante una simbolización de las dicotomías. 


\section{perifèria}

Número 6, Julio 2007

www. periferia. name

En este sentido, se impone hoy la necesidad acaso de un cambio de objetivos, que pasen por desactivar el antagonismo potencial de las relaciones sociales, por una renuncia al consenso racional y por la búsqueda de unas instituciones que transformen el antagonismo en agonismo. Son precisas, en este sentido, nuevas identidades democráticas y nuevas fronteras políticas (Mouffe, 1993, 12; Markoff, 2004).

La política en Occidente significa la combinación de "polis" y demos"; el objetivo de la política democrática no reside en eliminar las pasiones ni en relegarlas a la esfera privada, sino en movilizarlas y ponerlas en escena de acuerdo con los actores. No existe sin embargo un umbral de democracia que todos pudieran suscribir, sin asomo de duda, a causa del carácter frágil, incierto, quebradizo de la misma idea de democracia (Mouffe, 1993, 19). Sin embargo, piensa Mouffe que la perspectiva que más puede hacerla peligrar, incluso dejando a un lado toda su maleabilidad, es el racionalismo puro, sin vetas, en tanto que se muestra incapaz de comprender este desafío permanente al que ha de enfrentarse siempre cualquier régimen. Por esto, el racionalismo puro se queda ciego e impotente ante el conflicto.

La igualdad se ha proclamado como uno de los objetivos centrales de la política en occidente, al menos desde 1789, en su formulación teórica:

Si la igualdad es un objetivo central para nosotros, se debe a que vivimos en una sociedad democrática liberal en que las instituciones y los significados sociales están profundamente impregnados de este valor, que hace posible su utilización como criterio para discernir lo justo y lo injusto (Mouffe, 1993, 59).

Sin embargo, es más que sabido que esta igualdad teórica no posee un referendo en la igualdad de facto, lo cual puede hacernos pensar en hipocresía cuando nos sentimos capaces de denunciar la desigualdad de otros sistemas políticos o sociales en los que, acaso, tal "desigualdad" de autoridad o privilegios esté más controlada o, en cierto modo, aquilatada. En este punto, se hace ya preciso viajar a África. 


\title{
perifèria
}

Número 6, Julio 2007

www. periferia.name

\section{El espacio político en tradiciones africanas y lo político en África hoy: gestión de la memoria para la re-conciliación de identidades}

\begin{abstract}
La pluralidad de la persona es estructural (definir a un individuo supone situar a los demás), y la concepción de la herencia refuerza este carácter [...]. Por otro lado, si se presta atención al hecho de que cada cual tiene uno o varios vodún ${ }^{10}$ personales y que cada vodún contiene elementos materiales de los reinos animal, vegetal y mineral, se percibe fácilmente el inmenso esfuerzo de compendio del mundo que preside las concepciones de la persona, el dios y el rey, que convergen en una visión rigurosamente inmanente de lo social y la naturaleza (Augé, 2003, 60) [La negrita es mía].
\end{abstract}

Frente al racionalismo del Estado weberiano, se ha dicho que hay magia en el seno del poder social africano (Iniesta, 2005). Esta frase alude a unas realidades que han sido profusamente estudiadas en investigaciones empíricas, y muchos autores (Bayart, 1999; Chabal y Daloz, 2000) han refrendado la relevancia de fenómenos como la brujería, las lógicas faccionales o la explotación de linajes segmentarios en la gestión del espacio político poscolonial africano.

Sin embargo, caeríamos en un craso error si consideráramos las realidades políticas africanas como exentas de racionalidad y lógica interna, intrínseca, endógena, como toda lógica al fin y al cabo.

Hasta hace no mucho más de un par de décadas, los estudios empíricos y abordajes teóricos para el campo político africano solían partir de perspectivas ahistoricistas, e incluso folcloristas, de la propia trayectoria africana. Se inspiraban en un tratamiento de las culturas africanas como objetos de tradición inamovible, en lugar de como realidades dinámicas y, sobre todo, relacionales, como lo son en realidad todas las sociedades de la Tierra.

Ha sido Jean François Bayart uno de los más notables y rupturistas exponentes de la problematización de las sociedades africanas en términos de historicidad. Destruyó en buena medida los tópicos del "paradigma del yugo", caracterizado precisamente por la no historicidad (“[...] un paradigma capaz de devolver la

10 Los vodún en la cultura tradicional aladiana son espíritus de antepasados heredados por línea agnaticia patrilineal (pueblos guin y mina situados al este de Lomé, Togo) (Augé, 2003, 48). 


\section{perifèria}

Número 6, Julio 2007

www. periferia.name

historicidad al estado poscolonial africano"; Bayart, 1999, 315), y la consideración de las tradiciones inamovibles y de la "inautenticidad" africana a causa del mestizaje cultural que impuso la colonización.

Patrick Chabal y Jean-Pascal Daloz (2000) parten de la perspectiva de una no diferenciación (parcial, y no tan neta) del reino de lo político en África, lo que acarrea que su estudio involucre necesariamente un análisis de realidades tales como la corrupción (el clientelismo, el nepotismo), las elites y las clases políticas, la influencia del mundo de lo oculto, la brujería y la religión (tanto los sincretismos como los monoteísmos), la redistribución de prebendas en la interacción de la sociedad civil con las organizaciones no gubernamentales... Dicho de otro modo, se profundiza en los fenómenos circundantes a unos Estados débiles, minimizados frente a una proliferación de acciones populares, iniciativas económicas informales, vinculación intrínseca entre el poder (empoderamiento) y la acumulación económica.

Se discute cómo las elites y las distintas fuentes de emanación del poder llevan, desde la etapa colonial, estableciendo distintos tipos de relaciones más o menos exitosas con agentes externos y foráneos, lo que ubica África en una situación muy lejana a unas ciertas inmovilidad e incapacidad de acción que se quiso atribuir desde fuera durante mucho tiempo, e incluso desde dentro, desde la plataforma que significaron las intestinas luchas en el seno de los movimientos africanos de liberación nacional.

Se busca, asimismo, una nueva definición de lo político: ¿qué involucra, acarrea, incardina la política en África?

Separar los fenómenos pertinentes de lo que no lo son, decía Wolin, para definir qué es y qué no es política. Aquí se halla la diferencia fundamental entre espacios políticos que se revela entre occidente y África: los espacios políticos africanos se caracterizan por una no diferenciación de esferas que son propias de occidente. $Y$ esta no diferenciación no debe de ser vista, desde la acostumbrada prepotencia foránea y etnocentrista, como "incompletud" o como un proceso hacia el modelo occidental. No. Hablamos de desemejanzas intrínsecas y autóctonas, de modos 


\section{perifèria}

Número 6, Julio 2007

www.periferia. name

dispares de comprender la persona y su entorno, el mundo, el tiempo, las lealtades grupales y los colectivos nacionales.

La cuestión de la identidad política, por ejemplo, en sentido amplio es reconocida como crucial desde cualquier perspectiva teórica y práctica - como lo hicieron los mismos "hacedores de la liberación" africana-, por cuanto la construcción de una identificación ciudadana constituye una de las tareas más relevantes para la política democrática (Mouffe, 1993, 89ss). Ante las exigencias democráticas, que admiten una gran variedad de movimientos, la creación de identidades políticas puede constituir una forma colectiva de identificación (Mouffe, 1993, 102), mas no la única. Hay otros modos de pensar la identidad, más allá del que inspira el punto de partida del individuo. Si en la tradición occidental se incidía en la idea del espacio político como lugar común, en las tradiciones y devenir africanos la identidad es un lugar compartido.

La categoría de etnia, tan manida en el paisaje africano, es una de las posibles identidades o indicadores de identidad política, pero tampoco la única, ni necesariamente la más importante en todos los contextos frente a otras como la identidad familiar, de linaje, nacional, religiosa... (Bayart, 1999) ${ }^{11}$. En definitiva, estamos hablando de tipos diferentes y posibles de arraigo, de modos de creación de hegemonías y de articulación de poder, pero un poder que no es sólo institucional sino también social, que se expande en muchas áreas y en numerosos círculos (concéntricos) plausibles.

\footnotetext{
${ }^{11}$ La etnia, señala Bayart, es "sólo" una identificación más, un rasgo identificativo más, una pertenencia a un grupo más; no la única, desde luego, y acaso no la más definitoria, relevante, marcada o concluyente. Fue, eso sí, el rasgo que escogieron los colonizadores para organizarse (en el trato) y explotar más y mejor, por cuanto ofrecía réditos políticos para el "divide y vencerás" en la población (Bayart, 1999, 92ss).
}

Acaso la etnia resultaba para los colonizadores más fácilmente instrumentalizable que otros rasgos; o acaso, incluso, fue el rasgo que hallaron más asemejado al sentimiento de identidad nacional, de pertenencia a un país circunscrito territorialmente. Probablemente encontraron ahí más vecindad, pero también se encargaron de (re) crearla ellos mismos, incluso poniendo nombres donde no se conocían o no había designaciones concretas (etnónimos de cuño occidental).

Lógicamente el rédito político era bidireccional, así que no es de extrañar que los africanos también instrumentalizaran esas polarizaciones identitarias o designativas que la colonia hiciera de/con ellos; es sensato que se agruparan en torno a sus dinámicas, e incluso que, llegado el momento de la liberación, las utilizaran como plataformas reivindicativas, como un recurso a una "autenticidad" tradicional (re) inventada (lo que tampoco resta legitimidad, porque "reinventado" es todo). 


\section{perifèria}

Número 6, Julio 2007

www. periferia. name

Otra trampa a la que se ha sometido África es la del "sofisma de la gobernabilidad" o buen gobierno, juzgada externamente y a menudo considerada conditio sine qua non para la ayuda económica (vg. planes de ayuda estructural). ¿Por qué digo "sofisma", o paradoja, o trampa? Porque, ¿qué significa "buena gobernabilidad"? ¿Qué subyace a tal objetivo o voluntad política? Para empezar, ¿es la gobernabilidad un atributo o adjetivo atribuible a un gobierno o a una población? Si significa que la población reconozca la autoridad gubernamental y le guarde lealtad, ¿no habría que poner el énfasis primero en cómo es ese gobierno? No será bueno porque la gente lo quiera, sino que ésta lo querrá si es bueno.

La discusión sobre el buen gobierno, candente en la actualidad política, nos retrotrae a la reflexión sobre las condiciones profundamente desigualitarias de la globalización, por las que viene sucediendo una suerte de "universalización del apartheid" (De Sebastián, citado en López Castellanos, 2005). En efecto, el contexto de la globalización resulta ineludible -aunque sea como aspecto transversal- para el análisis de cualquier sociedad, y especialmente las africanas por las especificidades que se comenta. Resulta curioso notar que en el sistema mundial contemporáneo (o, para emplear la palabra más usada, en la era de la globalización) los flujos de intercambio económico a escala planetaria a menudo recuerdan al funcionamiento de redes clientelares (incluso horizontales) propias del funcionamiento de la economía en África, al menos de cierta parte de su economía.

La era poscolonial despierta muchos interrogantes nuevos para el analista político africanista. Frente al ya mencionado, y obsoleto, paradigma "del yugo" (Bayart 1999) para entender los procesos sucedidos en África tras las descolonizaciones, se impone la pregunta por la historicidad y la continuidad que muchas prácticas (económicas y políticas) coloniales tuvieron con prácticas autóctonas previas y posteriores. Dicho de otro modo, se reconoce una cierta gestión por parte de los propios africanos respecto del espacio político colonizado: si bien dentro de un

Así, la etnicidad es relacional y no sustancial (Bayart, 1999, 99). El fenómeno de la etnicidad, en África o dondequiera, no es esencialista; África no tiene "naturaleza", sino "historia", en este sentido.

Por otro lado, conviene recordar que los sistemas de dominación se nutren en buena medida de ideales de pureza. Frente a esto, de nuevo nos socorre Arendt (1974) cuando apela a una definición mixta de la condición humana, que pone la pureza misma bajo sospecha. 


\section{perifèria}

Número 6, Julio 2007

www.periferia. name

innegable sistema de desigualdad, no hubo pasividad en la recepción de los nuevos cánones, sino una adaptación creativa y fluida para con los mismos.

Esa capacidad de recreación continúa hoy bien visible en los procesos de generación de la identidad, siempre, como indica el mismo término "proceso", en tránsito. Toda identidad es relacional, no esencial o sustancial (Bayart, 1999, 99), y toda etnicidad es relativa, condicionada, con fecha de defunción incluso, al menos si se quiere entender siempre del mismo modo. Éste ha sido otro de los caballos de batalla de los analistas africanistas no africanos, siempre en pugna con sus propios prejuicios y cosmovisiones: la discusión en torno a la etnicidad, y la permeabilidad y ductilidad de las identidades étnicas.

Hoy, en la África de la poscolonia, las identidades políticas -y de otras índolessiguen recreándose constantemente en el juego del espacio político. A causa de la globalización, además, resulta importante de un modo especial redefinir y perfilar las propias identidades, ligadas intrínsecamente a la propia dignidad, la pertenencia y la susceptibilidad de ser nombrado (Taylor, 1993).

Los Estados poscoloniales africanos, que con frecuencia pueden definirse como personalistas, neopatrimoniales y extrovertidos, Estados a veces furiosos y a veces ociosos, muchas veces proyectos políticos en formación en lugar de Estados maduros (Ruiz-Giménez Arrieta, 2005), podrían acaso ser también acotados como naciones-Estado, en detrimento del limitado (y occidental) nombre de Estadonación (Donézar y Diez Ulzurrun, 2005)

En la África poscolonial los necesarios procesos de reconciliación pasan por dirimir la gestión de la memoria pública, y por ende de la memoria política. Cómo se habite en el espacio político local resulta, de este modo, crucial, ya que las facciones poderosas pueden fácilmente potenciar, incluso mediante políticas públicas de reconocimiento de patrimonio inmaterial, un recuerdo y no otro, un hecho en lugar de otro; pueden, en definitiva, redefinir la historia en los términos más convenientes o anhelados para un grupo concreto. 


\section{perifèria}

Número 6, Julio 2007

www. periferia. name

La etnogénesis (o génesis de categorías étnicas designativas en África), como construcción étnico-política, contribuye a fortalecer una re-construcción nacional, mediante la fatalización de un pasado de invasión y también la idealización del pasado precolonial.

Reinhart Kössler cuenta sobre Namibia cómo el líder Sam Nujoma, su sucesor Hikifepunyie Pohamba y la formación hegemónica SWAPO están llevando a cabo, mediante políticas de la memoria pública, una muy determinada selección de la historia. A través de la gestión del espacio y las construcciones públicos (el levantamiento de estatuas y ubicación de cementerios en lugares estratégicos, por ejemplo) denotan con mayor o menor sutileza el matiz querido: la preponderancia de SWAPO en la lucha por la liberación y, especialmente, unas mayores pluralidad en sus admisiones y democracia en sus medios de los que la historia "objetiva" puede refrendar (Kössler, 2003, 105, 107, 110) ${ }^{12}$.

Estos ejemplos muestran cómo la identidad es también una experiencia corpórea, que habita en el paisaje y en los imaginarios; y cómo permite, asimismo, la institucionalización de la mentira (Espaliat Larson, 2005). Otorgar un lugar específico a la memoria, aunque implique insuflarle vida, supone igualmente limitarla, acotarla; significa una cierta gestión del olvido, un trabajo con el olvido, y es que el tiempo mismo resulta en estos contextos una categoría de análisis en tanto que dimensión plástica, susceptible incluso de manipulaciones y fetichismos. Quien tiene el poder, político y económico, puede desarrollar más y mejores modos de activar o desactivar memorias, esas estrategias de desarrollo y olvido.

\footnotetext{
12 Otras vías, ya no físicas sino incluso intangibles, como la música, pueden confirmar categorías dominantes o por el contrario servir de voceros incendiarios en contra del statu quo. Siguiendo en Namibia, afirma Minette E. Mans: "Music is a powerful political tool" (Mans, 2003, 125), cuestionando la conveniencia de que también el arte deba estar al completo servicio de la construcción nacional, y por tanto bajo la "disciplina de partido", como parece suceder hoy en Namibia y con SWAPO a quince años ya de la independencia.

Un buen ejemplo de lo contrario, a saber, la música y la cultura musical como fuentes de rebelión y contracultura, lo ofrece George Yúdice (2002) sobre lo que llama la "funkización" de Río de Janeiro.
} 


\section{perifèria}

Número 6, Julio 2007

www. periferia.name

Es interesante considerar la utilidad política de la invención de mitos compartidos como los mitos constructores de nación-, así como es obvio que el de la ciudadanía es uno de los mitos más triunfantes en teoría política occidental. Los mitos de la ciudadanía nacen forzosamente distintos en África, así como la imagen buscada de los líderes.

No es baladí, como gran desafío del poscolonialismo, el desafío identitario frente a otros como el económico o el político a escala internacional. La gestión de la memoria pública e histórica, política, en este juego-desafío de las identidades poscoloniales y en el seno del Estado poscolonial lleva aparejada, en muchos casos, la palabra reconciliación. Esa re-conciliación no lo es sólo de unos grupos desemejantes de y con otros, sino que significa una nueva conciliación con la propia identidad y en el propio grupo, a menudo de contornos disímiles y porosos. "Sin justicia no hay paz social", dice Espaliat Larson (2005); y sin nuevas conciliaciones no hay identidad que resista a una historia (o, mejor dicho, historias) como la africana.

¿Quién tiene derecho a sacar conclusiones sobre la historia, en definitiva? El trabajo con la memoria es, sin duda, un juego de poder. No se puede contar "la verdad" de los otros y otras, pero sí hacer una confrontación de miradas, de verdades; sí ensayar la poliglosia o pluralidad de narrativas etnográficas y, en última instancia, de verdades humanas.

\section{Bibliografía}

Arendt, Hannah (1974). La condición humana. Barcelona: Seix Barral. Augé, Marc (2003). ¿Por qué vivimos? Barcelona: Gedisa.

Bayart, Jean-Françoise (1999). El Estado en África. La política del vientre. Barcelona: Bellaterra.

Chabal, Patrick y Daloz, Jean Pascal (2000). África camina: el desorden como Instrumento político. Barcelona, Bellaterra.

Constant, Benjamin (1919). “De la libertad de los antiguos comparada con la de los modernos". Escritos políticos. Madrid, Centro de Estudios Constitucionales, 1999.

Cyrulnik, Boris y MORIN, Edgar (2005). Diálogos sobre la naturaleza humana. Barcelona: Paidós I bérica. 


\section{perifèria}

Número 6, Julio 2007

www. periferia.name

Deleuze, Gilles y Guattari, Félix (1976). Rhizome. Introduction. París: Minuit.

Donézar Y Díez Ulzurrum, Javier (2005). “La descolonización en perspectiva histórica". Conferencia pronunciada en el curso "Descolonizar, intervenir, cooperar: África en el sistema internacional contemporáneo", celebrado en San Lorenzo de El Escorial del 18 al 22 de julio de 2005.

Dumont, René (2000). Democracia para África. Barcelona: Bellaterra.

Espaliat Larson, Astrid (2005). “Genocidio y actuación en el sistema penal internacional". Conferencia pronunciada en el curso "Descolonizar, intervenir, cooperar: África en el sistema internacional contemporáneo", celebrado en San Lorenzo de El Escorial del 18 al 22 de julio de 2005.

González Alcantud, José Antonio (1998). Antropología (y) política. Sobre la formación cultural del poder. Barcelona: Anthropos.

Iniesta Vernet, Ferrán (2005). "África y el mundo occidental: cinco siglos de frontera". Conferencia pronunciada en el curso "Descolonizar, intervenir, cooperar: África en el sistema internacional contemporáneo", celebrado en San Lorenzo de EI Escorial del 18 al 22 de julio de 2005.

Kössler, Reinhart (2003). "Public memory, reconciliation and the aftermath of war. A preliminary framework with special reference to Namibia". En MELBER, Henning (ed) (2003). Re-examining liberation in Namibia. Political culture since independence. Estocolmo: Nordiska Afrikainstitutet.

Mandela, Nelson (2005). Un camino nada fácil hacia la libertad. España: Zanzíbar. Mans, Minette E. (2003). "State, politics and cultura. The case of music". En Melber, Henning (ed) (2003). Re-examining liberation in Namibia. Political culture since independence. Estocolmo: Nordiska Afrikainstitutet.

Markoff, John (2004). "Construcción de la ciudadanía". Conferencia pronunciada el 24 de noviembre de 2004 en la Facultad de Filosofía y Letras, Universidad de Granada.

Palomar, Agustín (2005). “Bases para la roturación de un espacio político en La condición humana: contexto y justificación". El Búho, Época II, Año 2, no 3; Asociación Andaluza de Filosofía.

Peñas Esteban, Francisco (2005). "Procesos políticos y democratización en el África subsahariana: el pastel de la comunidad nacional". Conferencia pronunciada en el 


\section{perifèria}

Número 6, Julio 2007

www.periferia.name

curso "Descolonizar, intervenir, cooperar: África en el sistema internacional contemporáneo", celebrado en San Lorenzo de El Escorial del 18 al 22 de julio de 2005.

Ruiz Giménez-Arrieta, Itziar (2005). “El fracaso del Estado poscolonial”. Conferencia pronunciada en el curso "Descolonizar, intervenir, cooperar: África en el sistema internacional contemporáneo", celebrado en San Lorenzo de El Escorial del 18 al 22 de julio de 2005.

Sousa Santos, Boaventura de (2000). Crítica de la razón indolente. Contra el desperdicio de la experiencia. Bilbao: Palimpsesto.

Taylor, Charles (1993). El multiculturalismo y "la política del reconocimiento". (Ensayo de Charles Taylor. Comentarios de Amy Gutmann, C. Rockefeller, Michael Walter y Susan Wolf). México: Fondo de Cultura Económica.

Wolin, Sheldon (2001). Política y perspectiva. Bilbao: Amorrortu.

Yúdice, George (2002). El recurso de la cultura. Usos de la cultura en la era global. Barcelona: Gedisa. 